\title{
Training Interpreters With Compound Abilities-From the Perspective of Signed and Spoken Language Interpretation*
}

\author{
CHE Huan-huan \\ Leshan Normal University, Leshan, China
}

\begin{abstract}
Signed language is a natural language for verbal communication of the deaf and people hard of hearing. Both signed and oral language interpretation are activities that convert one language into another. They are similar with each other in terms of interpreting strategy, model, skills and so on. Sign language interpretation teaching and research can be integrated with oral interpretation teaching and research. China today urgently needs more multi-talented people than skillful language users. This paper holds if English majors learn signed language and can interpret between CSL, Chinese, and English, they must be warmly welcome in the employment market. Such interpreters with compound abilities are able to bridge the gap between hearing and deaf people even from different countries. This is of necessity and feasibility.
\end{abstract}

Keywords: signed language interpretation, English major, compound interpreters, translation studies

\section{Introduction}

Signed language has long been treated as an unsophisticated communication system manitaining incomplete linguistic features. Until 1960 when William Stokoe, father of American Sign Language (ASL) Linguistics, published his revolutionary work Sign Language Structure: An Outline of the Visual Communication Systems of the American Deaf, signed language began to be accepted by people as a natural means for verbal communication of the deaf and hard of hearing people, not an invented one. A signed language interpreter is a trained professional who facilitates communication and conveys both auditory and signed information so that both hearing and deaf individuals may interact. There are also interpreters who interpret different sign languages, such as CSL (Chinese Signed Language ) to ASL (American Signed Language ). During liaison interpretation of foreign affairs, when there are deaf people, both signed language interpretation and spoken language interpretation are needed. For instance, when foreign guests visit Chinese deaf people, an interpreter capable of both English and CSL is preferred. In Hong Kong, a few interpreters have such compound abilities; in the World Federation of the Deaf, some interpreters from developed countries can interpret between English and their native signed language. We can easily found the close relation between signed language and spoken language interpretation. Actually, translation study itself is interdisciplinary, no matter its theory or practice.

\footnotetext{
* Acknowledgements: This paper is an achievement for a key research project of Sichuan Special Education Development Research Center: Integrating Signed Language Interpretation to train Interpreters with Compound Abilities (No. SCTJ-2017-A02). CHE Huan-huan, associate professor, M.A., School of Foreign Languages, Leshan Normal University, Leshan, China.
} 
Under the reform and opening-up policy, the communication between China and other countries becomes more and more frequent. China has held and will hold more and more international competitions and conferences; China has received and will receive increasing official or civilian visit from abroad. Thus, signed language interpreters are urgently needed, for instance, in liaison interpretation, in competitions or performances where there are deaf people, in video remote interpreting, etc. Up to now, there have been two million deaf people in China. If both hearing and deaf people from different countries take part in an activity together, e.g., a deaf visiting mission travels around the world, the interpretation is not only between sign languages, spoken language interpretation is also quite often. In this case, signed language interpreters need to understand at least one foreign language, especially English. It is quite necessary.

\section{Theoretical Foundation}

In 1998, Mona Baker in her famous book Routledge Encyclopedia of Translation Studies illustrated signed language thoroughly and categorized it as the other kind of interpretation, which belongs to translation studies (see Figure 1). Wikipedia pointed out Interpretation describes immediate conversion of source (oral or text) orally (or by sign language), whereas translation is the conversion of source recorded oral, sign, or text to text. The Online Xinhua Dictionary put the explanation of translation/interpretation as: (1) to convert the meaning of one language or words of one country into another; and (2) to convert signals or figures into language or words. It is obvious that the definitions of "interpretation" include sign language. In fact, sign language interpretation is an essential part of interpretation.

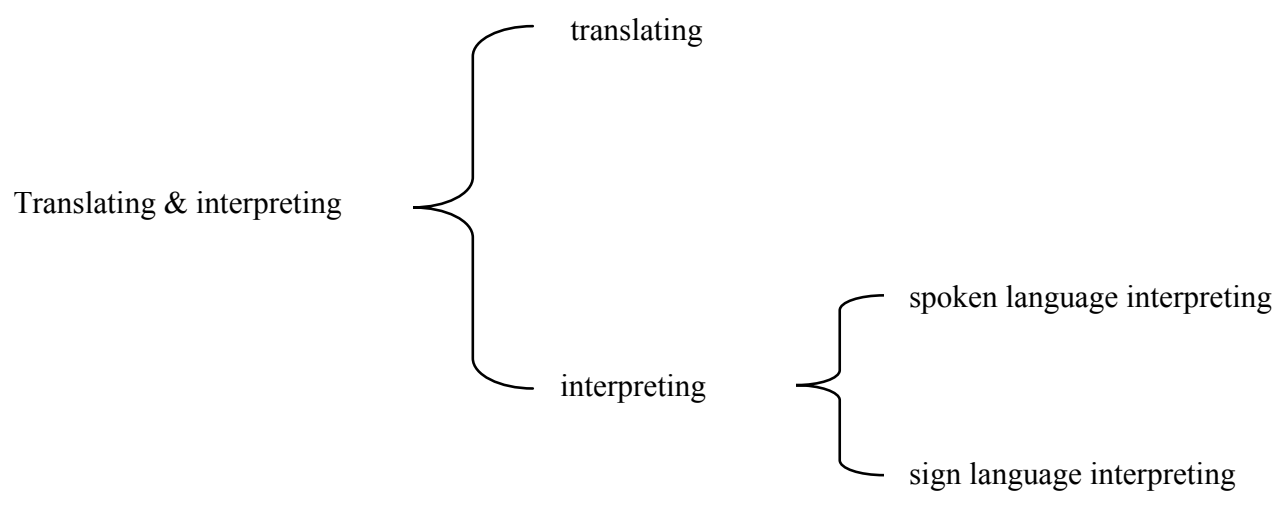

Figure 1. Classification of translating \& interpreting.

From it, we can also see signed language is included in interpretation. In fact, research on signed language has already been an important part of translation studies. As Ingram (1978) illustrated: "Signed language interpretation is an indispensable part of the study of interpretation. Any interpreting fails to take account of signed language interpretation is incomplete" (p. 56). While in China, theoretical research on sign language interpreting has just begun, usually as a very small branch of special education, which is dependent of translation studies. Its achievement is often prescriptive. As to this point, we need to learn from the research experience in developed countries such as America. Chinese famous scholar WANG Ji-hong (2011) also mentioned in Chinese Journal of Special Education that "interpreting has two modes: one is spoken-language interpreting and the other is signed language interpreting" (p. 33). 
Signed languages are used by 100 million deaf people all over the world and the most popular are American (ASL), Chinese, French, Brazilian, Russian, and British Sign Languages. There are almost 140 such languages according to the Ethnologue. What is more, Gestuno, or named International Signed Language, invented in 1975 by the British Deaf Association under the World Federation of the Deaf, is a constructed signed language and has been used in such venues as the Deaflympics. But its popularization is not optimistic because most people are get used to their own native signed language.

\section{Necessity of Training Interpreters With Compound Abilities}

Not until Jan. 1st, 2007 did the Ministry of Labor and Social Security in China announce sign language interpretation as a new formal occupation, which demonstrated the beginning of the professionalization of this newly emerging profession. In 2008 Beijing Paralympic Games, EXPO 2010 Shanghai, and Sichuan International Tourism Exposition 2015/2016, although we had many excellent interpreting volunteers, we were short of signed language interpreters and signed language interpretation was not carried out so smoothly and satisfactorily.

LIU (2015) held an investigation study on signed language translation requirements and service present situation for China's deaf community and drew the following conclusion: first of all, there is serious lack of sign language interpretation services in public places such as railway stations, hospitals, banks, and other places. The deaf community in need of interpretation services do not know where to seek help. Sign language interpretation services are in urgent need to help the deaf community to solve the problems that affect their daily life. Furthermore, the quality of signed language interpretation cannot meet the needs of the deaf community. Many Chinese signed language interpreters use gestures rather than natural sign language translation, especially in public media, such as TV news remote interpreting. Natural language is the native language of the deaf and signed language interpreters' gesture expression violates the natural signed language expression syntax requirements and is hard for the deaf to fully understand.

Now let us cast our eye on the English major graduates. Nowadays more and more people can speak English and some of them even have not been to college. English majors are not so popular in the employment market any longer. China today urgently needs more multi-talented people than skillful language users. If English majors can learn sign language and can interpret between CSL and English or even interpret between ASL, English, Chinese and CSL, they must be warmly welcome in the employment market. Such translators with compound abilities are able to bridge the gap between hearing and deaf people even from different countries. This is of great necessity and bears epoch-making significance.

Many Western countries admit signed language as an independent language in law and include it in national education system. What is more, the related training, testing, and certificating of sign languages are also established. In America, for example, more than 130 colleges and universities launch sign language as a major. While in China, there is a long way to go for signed language interpreters. Only four Chinese colleges or universities offer sign language major, they are Zhongzhou University, Nanjing Normal University of Special Education, Liaoling Yingkou Vocational College, and Zhengzhou Normal College. In Sichuan Province, no colleges or universities launch sign language major, but only offer sign language course in the major of special education. Leshan is a world famous international tourist city. There are many deaf tourists, but we have not even 
one tourist guide capable of sign language interpretation. In other words, there is a huge blank in the job market. In a long term, China is on the way to establish a socialist harmonious society; to train compound interpreters capable of both signed and spoken language interpretation creates barrier-free communication environment and benefits the nation and the people.

\section{Feasibility and Advantage of Training Compound Interpreters in Our University}

We have mentioned only four Chinese colleges or universities offer signed language major, while others only offer sign language course in the major of special education. Up to now, there are only four universities or colleges named Sichuan Normal University, Leshan Normal University, Chengdu College, and Sichuan University of Arts and Science offering the major of special education, under which signed language courses are launched. Among them our school—Leshan Normal University has a comparatively large scale of teaching and research. As to the academic level of graduates, Sichuan Normal University cultivates master degree graduates and the other three cultivate college degree or associate degree graduates; as to the history of the major, it is Leshan Normal University that has the longest history; as to the scale of students of the major, it is also our university - Leshan Normal University that has the largest scale; as to the teacher's educational and academic background, Sichuan Normal University is the best (SHE, 2013). Fortunately, it is not far away from our school and we can seek for some cooperation and communication if needed.

School of Special Education of Leshan Normal University used to be Special Education Department of Leshan Teachers College, which once ran a cooperative project of United Nations International Children's Emergency Fund in 1990-1994. As early as in 1990, our school offered special education major. In the year 2015, School of Special Education established. Scheme for a continuous course of five years is offered in majors like Art and Design for deaf students or students with hearing trouble. There is one national level training center for special education teachers and four provincial level research and training centers for special education teachers in our university. Our Experimental Training Building occupies 4,963 square meters, which is the largest building for special education in southwest of China and owns 32 different training rooms including signed language training room and hearing-speech rehabilitation training room. In addition, we have 34 internship bases such as special educational schools of different level, rehabilitation centers for the disable, etc., throughout China. Our teaching staff has carried out more than 30 international, national, or provincial projects. While school of Foreign Languages of our university has a history of more than 30 years. We have trained BTI (Bachelor of Translation and Interpteting) from the year 2014 with the cooperation of Xihua University. In recent years, Leshan Normal University has attached great importance to the professional capacity of graduates and paid much attention to BTI. Our school of Foreign Languages is one of the model centers of language teaching in Sichuan Province and enjoys abundant teaching resources. We have simultaneous interpretation training room, translation training room, and recorded studio. If School of Foreign Languages corporates with School of Special Education, it is feasible to train interpreters with compound abilities, capable of both signed and spoken language interpretation. We have already had on-line sign language courses offered freely on our campus net work and student club of sign language has developed step by step. Many of our English majors or translation majors choose sign language course as one of their elective courses and some of them have joined sign language club and take part in some activities such as being a volunteer interpreter in Sicuan International Tourism Exposition 2015/2016/2017. 
This is a very good beginning. In the future, the two schools can seek more chances to cooperate, such as offering Gestuno courses and carrying out more activities.

\section{Learning From Curriculum Provision and Teaching of Signed Language in America}

Since signed language interpretation is a new occupation in China, the practice of developed countries such as the United States could be used for reference. In the field of sign language interpretation, United States plays the leading role of the world. In the United States, more than 130 colleges and universities provide signed language interpretation major and offer courses at different levels. Let us take National Technical Institute for the Deaf of Rochester Institute of Technology as an example (MENG, 2010), when it comes to ASL-English interpretation program, the training objective is seemingly different from that of a Chinese university. Many bachelor's degree programs provide specialized preparation for students to develop interpreting skills as well as practical experience and coursework. Various courses are offered, such as: American sign language, deaf expressions, introduction to the field of interpreting, interpreting from English to ASL, interpreting from ASL to English, interpreting frozen and literary texts, educational interpreting: elementary settings, educational interpreting: middle/secondary settings, educational interpreting: post-secondary settings, transliteration, healthcare interpreting, mental health interpreting, introduction to legal interpreting, and introduction to cued speech transliterating. interpreting students enjoy small class and one-on-one discussions as well as advisement with knowledgeable faculty, building their strengths and developing their skills. It is obvious that the courses provided by Chinese university and colleges are relatively sign language-dominated. While in the United States, the ASL-English interpretation course is offered along with other interpreting courses.

In addition, the questions asked in the United States in its testing systems for competent signed language interpreters cover five areas, knowledge beyond signed language such as social and cultural system and social and political background of interpretation are also included (YANG, 2013). So we can easily get the following inspirations: First of all, it is suggested that the curricula of sign language interpretation major should add more interpretation courses. In the beginning of the paper, it is proved that both signed language interpretation and oral interpretation are similar with each other in terms of interpreting strategy, model, skills and so on. Since the main responsibility of signed language interpreters is to facilitate the communication through their sign language and interpreting skills, it is necessary to add more interpretation courses. Secondly, signed language interpretation major should be encouraged to be launched by more universities, colleges, or institutions. Thirdly, the role of signed language teachers should adapt to the requirements of sign language interpretation. Some language interpreters said when they were teaching in the classroom, for a long time they only acted as the role of discipline maintainer. This role of signed language teachers has strayed from the professional requirements of signed language interpreters themselves. Fourthly, the combination of higher education and short-term training is a good way to quicken the pace of training sign language interpreters. In addition, it would be a good deed if the government funds the training of signed language interpreters and provides more job opportunities for them. There is a huge employment blank of signed language interpreters in China. The low pay and the lack of regular job opportunities lag behind the professionalization of this occupation. 


\section{Conclusion}

Signed language is an independent language with its own grammar, syntax, and other linguistic features. Both signed and oral language interpretation are activities that convert one language into another one. There are similarities in terms of interpreting strategy, model, required skills and so on. We should integrate signed language interpretation research with oral interpretation research. In the field of teaching of sign language interpretation, we can learn from the United States who plays the leading role of the world. China today urgently needs more multi-talented people than skillful language users. It is possible and necessary for English majors to learn sign language and be able to interpret between CSL, Chinese, and English. In southwest of China, Leshan Normal University has a comparatively large scale and advanced teaching and research level in the field of special education, it is feasible for us to do some practical work to train interpreters with compound abilities, capable of both signed and spoken language interpretation, which must be warmly welcome in the employment market.

\section{References}

Baker, M. (1998). Routledge encyclopedia of translation studies. London and New York: Routledge.

Ingram, R. M. (1978). Sign language interpretation and theories. Berlin: Plenum Press.

LIU, Z. X. (2015). Signed language translation requirements and service present situation for China's deaf community (pp. 2-3). Chongqing: Chongqing Normal University.

MENG, F. L. (2010). Some inspiration from signed language teaching in America. Journal of Zhongzhou University, 24(4), 41-43.

MENG, F. L. (2013). Situation, problems and solutions of special education in China. Journal of Zhongzhou University, 22(3), $87-90$.

Napier, J. (2004). Sign language interpreter training, testing and accreditation: An international comparision. Washington, D.C.: Gallaudet University Press.

Roy, C. B. (2000). Innovative practices for teaching sign language interpreters. Washington, D.C.: Gallaudet University Press.

SHE, W. B. (2013). SWOT analysis and development strategies of special education major in Sichuan province. Journal of Chifeng College, 30(6), 243-247.

WANG, J. H. (2011). Inspirations of Austrlian signed language integration. Journal of Chinese Special Education, 55(7), 33-47. Wikipedia (n.d.). Interpretation. Retrieved July14th, 2017 from https://en.wikipedia.org/wiki/Language_interpretation

YANG, T. (2013). Enlightment from comparison of sign language interpretation in China and U.S. (pp. 15-17). Xian: Xian International Studies University. 